\title{
Labour market transitions, shocks and institutions in turbulent times: a cross-country analysis
}

\author{
Ronald Bachmann ${ }^{1,2,3,4} \cdot$ Rahel Felder ${ }^{1,5}$
}

(C) The Author(s) 2020, corrected publication 2021

\begin{abstract}
This paper analyses the impact of the business cycle on labour market dynamics in EU member states and the US during the first decade of the 21st century. Using unique measures of labour market flows constructed from worker-level micro data, we examine to what extent macro shocks were transmitted to national labour markets. We apply the approach by Blanchard and Wolfers (Econ J 110(462):1-33, 2000) to analyse the role of the interaction of macroeconomic shocks and labour market institutions for worker transitions in order to explain cross-country differences in labour market reactions in a period including the Great Recession. Our results suggest a significant influence of trade unions in channelling macroeconomic shocks. Specifically, union density moderates these impacts over the business cycle, i.e. countries with stronger trade unions experience weaker reactions of the unemployment rate and of worker transitions.
\end{abstract}

Keywords Worker flows · Labour market dynamics · Institutions · Great recession

Mathematics Subject Classification J6 · E24 · E32

We thank Thomas K. Bauer, Daniel Baumgarten, Giuseppe Bertola, Romain Duval, Hanna Frings, Matthias Giesecke, Philipp Jäger, Lisa Leschnig, Pedro S. Martins, Christian Merkl, Battista Severgnini as well as participants of the 30th Annual Congress of the European Economic Association, the IZA/OECD Employment Seminar, the World Bank DIME seminar, the "Conference in honor of Christopher A. Pissarides" at SciencesPo, Paris, the FAU/IAB-Seminar Macroeconomics and Labor Markets in Nürnberg, the 9th RGS Doctoral Conference in Economics, the 21st SMYE, the Jahrestagung of the Verein für Socialpolitik 2016 and seminars at RWI for helpful comments and suggestions. We are grateful to Fernanda Martinez Flores for excellent research assistance.

Electronic supplementary material The online version of this article (https://doi.org/10.1007/s1066 3-019-09469-y) contains supplementary material, which is available to authorized users.

Ronald Bachmann

Ronald.Bachmann@rwi-essen.de

Extended author information available on the last page of the article 


\section{Introduction}

The recent Great Recession was associated with job losses and displacements for a substantial number of persons, and a strong and persistent increase in unemployment in many European countries. The average unemployment rate in the Eurozone rose from an average of $7.0 \%$ in 2008 to $10.9 \%$ in 2013 (Eurostat 2014). This figure, however, masks large divergences in labour market reactions across the EU and associated countries (European Central Bank 2012; OECD 2013). In Austria, Belgium, Germany, Luxembourg and Norway the unemployment rate hardly increased during the crisis, whereas in Estonia, Greece and Spain, it rose strongly, reaching a level of $25 \%$. Worker flows which determine the level of unemployment, exhibit substantial heterogeneity as well (Bachmann et al. 2015). For certain countries, an increase in job losses during the Great Recession led to large outflows from employment, while for others a decline in job creation led to small outflows from unemployment. These cross-country differences are not only likely to be strongly influenced by cross-country differences in the magnitude of economic shocks, but also by the institutional framework of national labour markets.

In this paper, we therefore investigate the role of labour market institutions for the transmission of macroeconomic shocks to labour markets looking at both the unemployment rate and worker flows. In particular, we apply Blanchard and Wolfers' (2000) empirical method which was originally used to examine the causes of diverging development of US and European unemployment from the 1960s until the mid-1990s. ${ }^{1}$ By contrast, our analysis focuses on cross-country differences in unemployment and labour market dynamics between 1999 and 2013, a period covering the Great Recession, for a large number of European countries as well as the US. We enhance their model by allowing for changes in institutional variables over time, which accounts for the variation of institutions within countries as motivated by Nickell (1997). Specifically, we analyse the impact of shocks and the interaction of shocks and labour market institutions. We separately identify (i) the direct impact of macroeconomic shocks and (ii) how shocks of a given size were transmitted to the national labour markets through the prevailing institutional framework. The latter thus measures the indirect effect of institutions on labour market dynamics.

The main result of our analysis concerns the role of trade unions in shaping macroeconomic shocks for labour market dynamics. In particular, higher union density is associated with more moderate labour market reactions in recessions as well as in economic upturns. One explanation is the objective of trade unions to provide job security to their members, which leads to both lower employment growth in economic upturns and lower job destruction in recessions. As this result has not been found by the preceding literature, it seems to be a particular phenomenon of the time period leading up to and including the Great Recession. Furthermore, our results lend support to findings from the literature that employment protection legislation becomes more important for labour market flows

\footnotetext{
1 Note that this methodology does not yield causal effects. The word "effect" should therefore be broadly interpreted in the following.
} 
when the trend growth of the economy is low (e.g. Bentolila and Bertola 1990; Messina and Vallanti 2007).

Our analyses are related to two strands of the economic literature. On the one hand, there is a considerable and rapidly growing literature on worker flows, focusing on the mechanisms underlying the cyclical behaviour of the unemployment rate. These studies investigate the relative importance of the inflows into and the outflows from unemployment, with the most recent articles establishing a relatively balanced role of inflows into and outflows out of unemployment (e.g., Elsby et al. 2009; Yashiv 2008; Fujita and Ramey 2009).

On the other hand, our paper is connected to a large body of theoretical and empirical literature examining heterogeneity in the unemployment rate caused by institutions across and within countries. An overview of these studies is provided by Boeri and Van Ours (2013). In theory, labour market institutions can have ambiguous effects on labour market performance as they play two contrasting roles. First, they may worsen labour market outcomes by forming rigidities which distort price- and wage-setting mechanisms (Layard et al. 1991, 2005; Blanchard 1999); second, they may have positive effects by disseminating information and increasing coordination (Traxler and Kittel 2000) in the labour market.

Bassanini and Duval (2006), Eichhorst et al. (2010), Orlandi (2012), Flaig and Rottmann (2013), de Serres and Murtin (2013), Gal and Theising (2015) and Bertola (2017) represent recent examples of empirical research applying crosscountry comparisons. They provide evidence for an adverse effect of generous unemployment insurance systems and large tax wedges on unemployment. In contrast, high levels of wage bargaining coordination and active labour market programmes exert a favourable influence. Only Eichhorst et al. (2010) cannot find support for the relevance of classical labour market institutions, but they attribute a key role to the internal flexibility of labour markets.

Our contributions to the literature are as follows. First, we extend the framework of Blanchard and Wolfers (2000) which has been extensively used to examine differences across countries in labour market stocks, especially unemployment, to an analysis of labour market transitions. Taking into account worker transitions allows us to investigate the behaviour of national labour markets over the business cycle more precisely, since flows are generally more sensitive to macroeconomic shocks and respond more quickly than it is the case for stocks, which could especially be seen in many European countries during the Great Recession (Bachmann et al. 2015). The analysis of worker flows yields insights into the mechanisms underlying the dynamic components of employment and unemployment, which is at the core of the "ins vs. outs" debate. Our study provides indications regarding potential institutional reasons for cross-country differences in the relative contribution of inflows into and outflows from unemployment being highly policy relevant. Moreover, labour market transitions are measures of employment security (for worker flows from employment to unemployment) and of unemployment duration (for worker flows from unemployment to employment). As high employment security and low unemployment duration are valued by workers, our study provides welfare implications of labour market institutions. 
Second, we investigate labour market behaviour during the time period 1999 to 2013 , i.e. the Great Recession and the preceding decade. ${ }^{2}$ This period is particularly interesting as it includes a long expansion with strong employment creation in many industrialised countries, as well as the Great Recession which featured an economic shock much larger than what could be seen in previous recessions. This leads to relatively high variation in our restricted sampling period which enables us to investigate the transmission of shocks through institutions to national labour markets. Finally, in contrast to many existing studies, we analyse the entire first decade of the 21 st century. Therefore, we take into account the (medium-run) effects of important changes in labour market institutions that had taken place in or just before this decade in many Southern European countries such as Italy and Spain, but also Central European countries such as Germany.

The remainder of the paper is structured as follows. Section 2 describes the data used to construct the measures for labour market dynamics and for macroeconomic shocks as well as provides descriptive evidence for the 21 countries in our sample. Section 3 illustrates labour market institutions and reviews their potential impact on labour market dynamics from a theoretical point of view. Section 4 explains the empirical identification strategy. Section 5 presents the results, including a set of robustness tests. The last section summarizes the main findings and concludes the discussion.

\section{Unemployment and labour market flows over the cycle}

Our sample of analysis consists of 20 European countries ${ }^{3}$ as well as the US. We obtain labour market dynamics of European countries from the European Labour Force Survey (EU-LFS) which is based on a large number of representative national household surveys. It includes all EU Member States without Croatia (EU 27) as well as Norway, Iceland and Switzerland. The Labour Force Surveys are conducted by the national statistical agencies applying harmonized concepts and definitions, which enables us to perform a cross-country comparison. From a person's current and previous labour market status, we compute the stock of employed, unemployed and non-participating individuals, along with transition rates between every labour market state by year and country. In the data, an individual's current labour market status is defined according to the ILO standard. ${ }^{4}$ By contrast, the labour market status in the previous year is based on self-perception of the interviewed person.

\footnotetext{
2 The analysis of the evolution of unemployment by Bertola (2017) also includes the time period of the Great Recession.

3 The countries are Austria, Belgium, Czech Republic, Germany, Denmark, Estonia, Spain, Finland, France, Greece, Hungary, Italy, Luxembourg, Norway, Poland, Portugal, Sweden, Slovenia, Slovak Republic and the United Kingdom.

4 This means that a person is defined as employed if he or she performed some work for wage/salary or for profit or family gain, or - if temporarily not at work - had a formal attachment to his or her job or was with an enterprise; and as unemployed if he or she was without work, currently available for work, and seeking work (ILO 1988).
} 
Although these two definitions might not overlap perfectly, using both to identify labour market flows from one year to the next is preferable to alternative approaches, which would not allow for a consistent approach across countries (see online appen$\operatorname{dix} B$ ).

US data on labour market status and worker transitions are taken from the IPUMS-CPS database (Flood et al. 2015), which is derived using the Current Population Survey (CPS). In order to make worker flows comparable with the EU-LFS, we impose the time structure of the EU-LFS data set on the CPS data. In particular, for each month of the observation period, we construct stocks and flows for individuals observed in the same month one year before. For each year, the monthly values are averaged yielding one measure for each labour market outcome per year.

In our analysis, we focus on the time period 1999 to 2013. This time period corresponds to the largest number of available country-year combinations for which information on labour market transitions is available in the EU-LFS. As explained in detail in the online appendix B, we exclude several European countries from the EU-LFS because of limited data availability; for the same reason, we need to impute some missing values. The final data set includes the unemployment rate and transition rates between employment and unemployment at the country-year level. At the individual level, we restrict the sample to dependent-status employees, and omit individuals living in institutional households (e.g. retirement homes or military barracks), working for the military as well as children under the age of 15 and adults aged 65 and over.

The initial observation motivating our analysis is that changes in the unemployment rate and in the worker flow rates between employment and unemployment show large cross-country variation over the business cycle, especially during the Great Recession, a period of strong labour market turbulence. Figure 1 illustrates these differences by relating the changes in annual GDP growth to changes in unemployment and the transitions between employment and unemployment from 2007 to 2008. This makes clear that countries with very similar changes in GDP, such as Austria, Italy and Spain - with a reduction in GDP growth of about 3 percentage points - differ considerably in their labour market reactions.

This suggests that similar macroeconomic shocks were transmitted heterogeneously to national labour markets. Furthermore, the response in the transition rate from unemployment to employment was of comparable size, but the reverse worker flow and therefore the unemployment rate exhibited extremely contrasting trends. This is an indication that the answer to the "ins vs. outs" debate is likely to differ between countries (see. e.g. Petrongolo and Pissarides 2008 and Elsby et al. 2013 for an explicit cross-country analysis of these issues).

Looking at our variables of interest in more detail, we first focus on macroeconomic shocks. In order to proceed as parsimoniously as possible, we use the most aggregate measure of the business cycle available, the annual growth rate of real GDP. ${ }^{5}$ The annual GDP time-series for countries provided by the OECD allows us

\footnotetext{
5 Alternative measures of the business cycle are for example the output gap, the real interest rate and total factor productivity growth, which we apply in robustness tests (see Sect. 5.2).
} 
(a) Unemployment rate

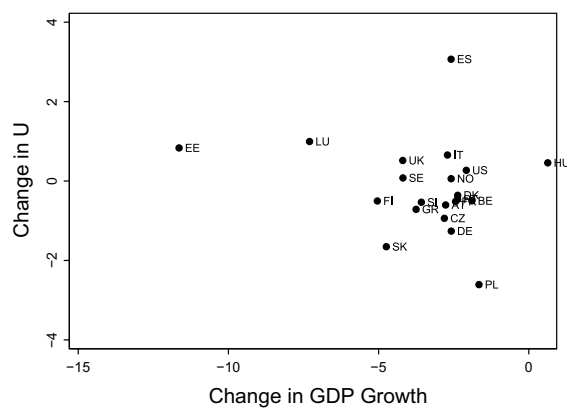

(b) Transition rate from employment to unemployment

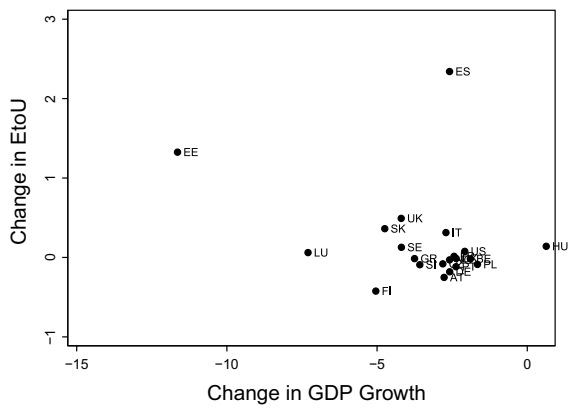

(c) Transition rate from unemployment to unemployment

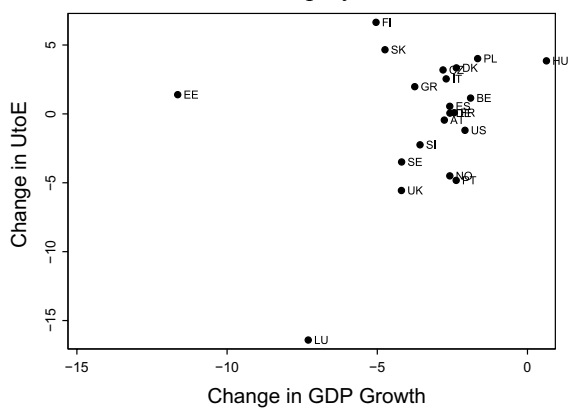

Fig. 1 Relationship between annual GDP growth and labour market reactions at the beginning of the Great Recession, 2007 and 2008. Notes: Country codes: AT: Austria, BE: Belgium, CZ: Czech Republic, DE: Germany, DK: Denmark, EE: Estonia, ES: Spain, FI: Finland, FR: France, GR: Greece, HU: Hungary, IT: Italy, LU: Luxembourg, NO: Norway, PL: Poland, PT: Portugal, SE: Sweden, SI: Slovenia, SK: Slovak Republic, UK: United Kingdom, US: United States of America. Source: EU-LFS, CPS, ICTWSS, own calculation

to compute economic growth rates. Figure A.1 in the online appendix shows that all countries experienced country-specific stable growth levels with moderate business cycle movements in the time period 1999 to 2007, except for a dip in the early 2000s driven by the new economy recession which followed the dot-com bubble. In 2007/2008, when the Great Recession hit economies, an extreme reduction in GDP growth in most countries is visible. The extent of the fall was heterogeneous across countries. While the recession was relatively mild in countries such as Norway, the US, France, Belgium and Germany, where the decrease in the growth rate is at most 3 percentage points, it was rather strong in Slovenia, Slovakia and Estonia with a decline of up to 11 percentage points. Furthermore, in the aftermath of the recession, some countries such as Estonia and the US, recovered relatively quickly, whereas other countries such as Greece and Spain, faced a protracted recession.

Turning to the detailed descriptive evidence on the unemployment rate and labour market transitions, clear cyclical features become apparent for the time 


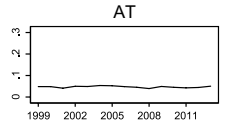

EE

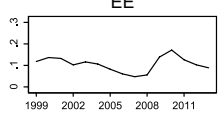

$\mathrm{HU}$

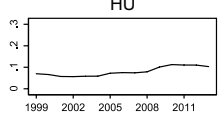

PT

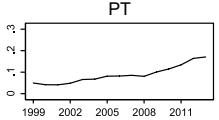

US

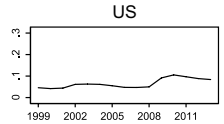

$B E$

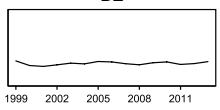

ES

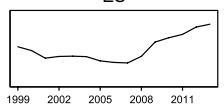

IT

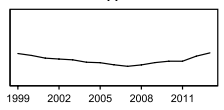

SE

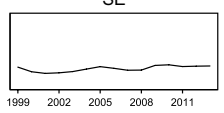

$\mathrm{CZ}$

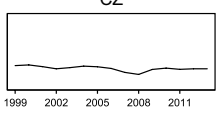

FI

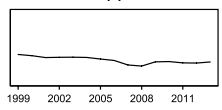

LU

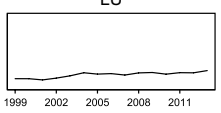

SI

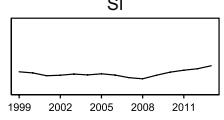

$\mathrm{DE}$

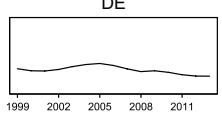

FR

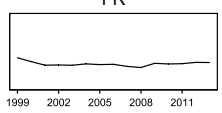

$\mathrm{NO}$

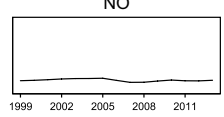

SK

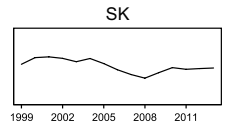

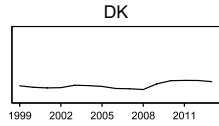

GR

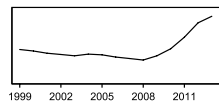

PL

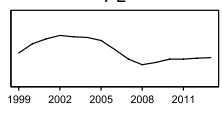

UK

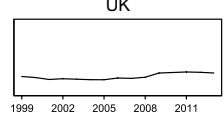

Fig. 2 Unemployment rate by country, 1999-2013. Notes: See Fig. 1 for the country codes. Source: EULFS, CPS, own calculation

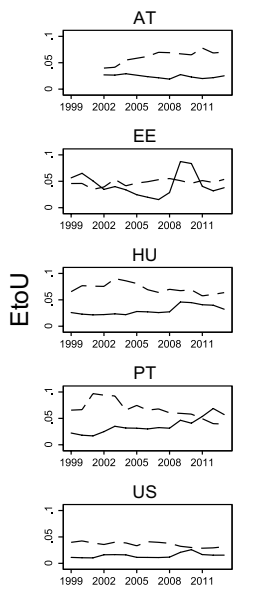

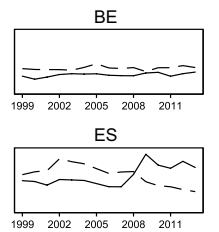

IT

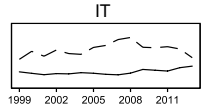

SE

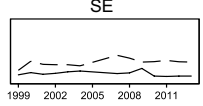

$19992002 \quad 2005 \quad 20082011$

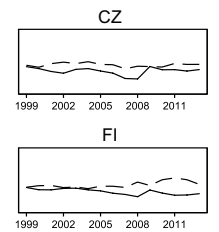

LU

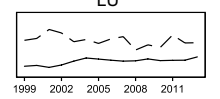

SI

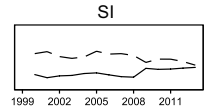

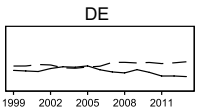

FR

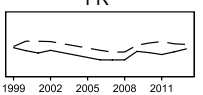

NO

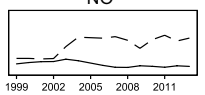

SK

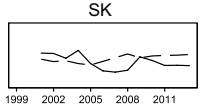

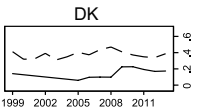

GR

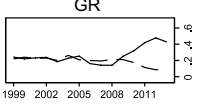

$\mathrm{PL}$

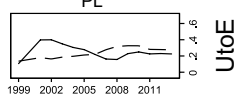

UK

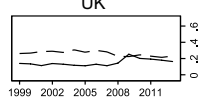

Fig. 3 Annual transition rates between employment and unemployment by country, 1999-2013. Notes: See Fig. 1 for the country codes. Transitions from employment to unemployment are plotted against the primary axis. Transitions from unemployment to employment are plotted against the secondary axis. Source: EU-LFS, CPS, own calculation

period 1999 to 2013 (Figs. 2 and 3): The unemployment rate and the transition from employment to unemployment were countercyclical, whereas the transition from unemployment to employment was procyclical. This pattern was especially strong in 2007 and 2008, the beginning of the Great Recession. In addition, the figures indicate that the extent of labour market reactions at the start of the 
recession and their persistence in the following years varied remarkably across countries.

In particular, the adverse responses in the unemployment rate during the Great Recession range between one percentage point in the Czech Republic to 14 percentage points in Spain (Fig. 2). In countries where the unemployment rate rose considerably, it remained stubbornly high until 2013. An exceptional case is Estonia. After the rate peaked in 2010, it decreased quickly, almost going down to its initial level. Only a few countries experienced hardly any change or even a decrease in unemployment during the observation period. For example, the unemployment rate was stable in Austria, Belgium, Finland, Norway and Poland; in Germany it fell during most of the recession years. ${ }^{6}$

A heterogeneity of similar extent emerges for the transition rates from employment to unemployment and unemployment to employment. Changes in worker flows from employment to unemployment were especially big in 2008, which is in line with expectations (Fig. 3): At the start of the recession, the large adverse shock raised job destruction, increasing the transition rates from employment to unemployment. Countries which were strongly hit by the economic downturn, such as the US, Spain, Greece, Portugal and Estonia, experienced a substantial rise in the corresponding rate of up to 7 percentage points. However, they display very different speeds of recovery. The transition rate in the US dropped to almost its pre-recession level in 2011, whereas in Hungary it was still above the respective value in 2013. Again, Germany was an exception as the transition rate from employment to unemployment decreases slightly during the Great Recession.

The evolution of worker flows from unemployment to employment shows pronounced trends in a number of countries, together with some business cycle turbulence (Fig. 3). In economic downturns job creation and, hence, hirings are lower. Therefore, the transition rate from unemployment to employment decreases. Indeed, this is the case for most of the countries during the Great Recession. The initial drop was the highest in Spain, Italy and Norway where it equalled roughly 20 percentage points. However, some countries, such as Austria and Poland, experienced an increase in this transition rate. Since the variation of the rate within a country over time is high, it is not feasible to draw conclusions on the speed of recovery.

\section{Labour market institutions and their interaction with shocks}

The main question arising from the descriptive evidence above is whether and how national labour market institutions are responsible for differences in the labour market reactions to macroeconomic shocks. Looking at the indicators for employment protection legislation and union density supports the intuition that labour market institutions exert an indirect, rather than a direct, influence on national labour markets, since the measures vary little over the observation period within countries

\footnotetext{
${ }^{6}$ See e.g. Burda and Hunt (2011) and Burda and Weder (2016) for an analysis of the German experience during the Great Recession.
} 
(Figs. A.2 and A.3 in the online appendix respectively). Moreover, the level of the indicators differs substantially across countries. To go back to the previous example: While Italy and Spain were similarly hit by the Great Recession, they display very dissimilar labour market reactions, which could be explained by union density being substantially higher in Italy compared to Spain. Taken together this indicates that institutions amplify or diminish the impact of economic turbulence.

Specifically, labour market institutions influence the transmission of economic shocks to national labour markets in a twofold manner. Initially, they affect the intensity of a shock hitting the labour market and later the adjustment process back to the steady-state level. Institutions describing the flexibility of labour markets by creating wage or employment rigidities exhibit both attributes, whereas institutions influencing the reservation wage and job search intensity relate mainly to the adjustment process.

Following Blanchard and Wolfers (2000) we capture the institutional setting of national labour markets by using eight indicators. ${ }^{7}$ They cover the unemployment insurance system, employment protection legislation (EPL), the collective bargaining system, active labour market policies (ALMP), and the tax burden of employees for each country. Table A.1 in the online appendix depicts descriptive statistics of our variables and illustrates their size, variation and availability. ${ }^{8}$ The correlation between the various institutions is overall strong and positive (Table A.2 in the online appendix). For instance, strict EPL is significantly positively correlated with all indicators except for union density. This poses a challenge for our empirical analysis which we address using different strategies in our benchmark models as well as in robustness tests (see Sect. 4 for a discussion).

We next describe the economic rationale for each of these indicators. From a theoretical point of view, trade unions take centre stage in the determination of wages. In a right-to-manage model (Nickell and Andrews 1983), unions and employer organisations negotiate over wages, which are then taken as given by individual firms in their decision over employment. Thus, higher trade union power is associated with higher wages. By contrast, in an efficient bargaining model (McDonald and Solow 1981), both wage and employment are bargained over, which implies that an increase in trade union power does not necessarily cause adverse effects.

Nevertheless, trade unions can create wage rigidities being especially relevant for the responsiveness of wages to a change in aggregate economic conditions. In particular, with higher downward wage rigidity initially more job matches are destroyed as a reaction to a large adverse shock, leading to higher worker transitions from employment to unemployment and a stronger increase in unemployment (Bertola and Rogerson 1997). Yet, the overall influence of trade unions in economic turbulence is not clear-cut, because trade union's aim to protect the

\footnotetext{
${ }^{7}$ The institutional measures are the replacement rate of unemployment benefits and their length, employment protection legislation, union coverage, union density, the level of wage bargaining, active labour market policies and the tax wedge.

${ }^{8}$ See the appendix B for a detailed description of the shocks and institutions variables, as well as the respective data sources.
} 
jobs of their members (Freeman 1978; Medoff 1979) which can mitigate extreme reactions of labour markets. On the one hand, the job security motive generates a scope for modification at the intensive margin, e.g. reducing working hours in order to prevent job losses. This goes along with lower adverse labour market reactions and a faster recovery of the economy. On the other hand, the same motive fosters the segregation of labour markets making it harder for outsiders, the unemployed, to enter employment. Thus, during an economic upturn strong trade unions might affect the buildup of the employment stock, thereby hindering the reduction of unemployment. Taken together, these effects lead to low variation in the unemployment and employment stocks over the business cycle. This is in line with evidence presented by Pierse and McHale (2015), Goerke and Pannenberg (2011) and Ivlevs and Veliziotis (2017) who find that union membership decreases the probability of dismissal for the UK, Germany and countries from Central and Eastern Europe, respectively. Also, Hijzen and Martins (2016) investigating government-issued extensions in collective bargaining coverage confirm this relationship. Overall however, not only the size of the trade unions is important, but also the structure of collective wage bargaining (Traxler and Kittel 2000) which influences the capability of national labour markets to internalize detrimental effects caused by asymmetric information. We therefore consider three measures of wage-setting institutions in our empirical analysis: Union coverage, union density and the coordination of the bargaining process.

Employment protection legislation (EPL) measures employment rigidity. EPL represents the costs that arise for firms in case of the dismissal of an employee and is an indicator for the flexibility of a labour market. In a simple steady-state search-and-matching model of the labour market, the following mechanism holds (Mortensen and Pissarides 1999): The stricter EPL, the more costly it is for employers to lay off workers, which reduces worker outflows from employment. Because employers are forward-looking, it also decreases vacancy creation and therefore inflows to employment. Therefore, EPL lowers labour turnover with ambiguous effects on unemployment. There exists empirical evidence in line with this theory: Higher EPL is associated with lower aggregate labour market flows, and there is no clear association between EPL and the unemployment rate (Scarpetta 1996; Nunziata 2002). However, this picture changes when considering varying business cycle conditions as the impact of EPL on labour market dynamics has been shown to be more important under lower trend growth than under higher trend growth, both theoretically (Bentolila and Bertola 1990) and empirically (Messina and Vallanti 2007).

The relation of EPL, economic turbulence and the labour market is thus straightforward. In economic upturns firms will hire less employees if EPL is high, which leads to lower employment growth. Similarly, at the beginning of recessions, strict EPL is associated with lower unemployment since firms cannot adjust properly to the situation. This mechanism also hinders the recovery process. Thus, over the business cycle, EPL affects both the initial impact of an economic shock as well as its persistence on the labour market. However, this effect is likely to vary over the business cycle. In our empirical analysis, we therefore study the link between EPL and labour market dynamics for the whole time period investigated, as well as separately by boom and recession periods. Furthermore, we use the EPL measure 
governing regular employment which applies to workers with permanent contracts on labour market dynamics, as this is generally the most prevalent employment type.

Next, we concentrate on labour market institutions that influence individuals' job search intensity and the reservation wage of the unemployed. In theory, both affect only the adjustment process of the labour market back to the steady-state after economic turbulence. One of the most important institutions in this context is the unemployment insurance system. The likelihood of taking up a job decreases when unemployment benefits are higher and when benefit entitlements are longer, since these factors lower the incentives to search for work. At the same time due to lower opportunity costs of unemployment, a generous unemployment insurance pushes up the reservation wage. Indeed, empirical evidence suggests that unemployment benefits have a significant adverse effect on unemployment and on worker flows from unemployment to employment (among others Nunziata 2002; Nickell et al. 2005; Schmieder and von Wachter 2016).

As for cyclical features in this context, by the same reasoning we expect that during economic upturns, a more generous unemployment insurance system goes together with a higher unemployment rate and lower unemployment to employment transitions. During recessions a similar mechanism is likely to apply. However, the job market perspectives of unemployed persons worsen irrespective of the generosity of the unemployment insurance system, which means that the moral hazard induced by a generous unemployment insurance system may be lower in recessions than in booms (Schmieder et al. 2012). Among the variables characterizing the unemployment insurance system, we choose the benefit replacement rate and the duration of unemployment benefits. While the replacement rate captures the level of unemployment benefits relative to previous earnings, benefit duration measures how long individuals are entitled to unemployment benefits.

Taxes relate to both job search intensity and the reservation wage, too. The labour tax wedge measuring the difference between the labour costs to the employer and net take-home pay of the employee increases the reservation wage and reduces the efforts of an unemployed individual to search for a job. Therefore, it is associated with lower transitions from unemployment to employment and higher unemployment. However, Blanchard and Wolfers (2000) argue that this effect is small, because the labour tax wedge contains, among others, payments for health benefits and retirement. Nevertheless, many empirical studies find a strong adverse relationship between the tax wedge and unemployment (Belot and Van Ours 2004; Nickell 1997).

On the labour supply side, the tax wedge can be expected to have a similar influence as the unemployment insurance system. That is, during economic booms the tax wedge is adversely related to outflows from unemployment and to the unemployment rate. During recessions the interaction is expected to be negligible. In addition, however, one can expect effects on the labour demand side, with a high tax wedge implying labour costs and thus reducing labour demand. This could amplify the negative labour-market effects in a recession.

Active labour market policies (ALMP) influence the labour market mainly via changes in job search intensity. ALMP programmes aim at reducing unemployment by improving the job matching process and by enhancing opportunities for 
unemployed to accumulate skills and work experience affecting their job search behaviour. Thus, unemployed individuals become more employable. In theory, programmes of this type lower the unemployment rate as transitions from unemployment to employment increase. In practice, this effect has been shown to depend strongly on the specific programme design (Card et al. 2010, 2018). Concerning the channelling and persistency property with respect to adverse macroeconomic shocks, ALMP does not influence the initial depth of a downturn, but in contrast exerts a positive impact on the recovery of the labour market by supporting recently unemployed to get back into work. By contrast, the impact of such programmes has been shown to be much smaller in a recession than in a recovery (Card et al. 2018).

\section{Methodology}

The aim of our empirical analysis is to examine the medium-term developments of European and US labour markets dynamics over the time period 1999 to 2013 . We apply the empirical methodology of Blanchard and Wolfers (2000) to investigate the importance of the interaction of macroeconomic shocks and labour market institutions for the unemployment rate and worker flow rates. In doing so, we estimate an econometric model which allows for observable and country-specific shocks and which therefore takes into account differences in GDP growth between countries, which includes the depth of the Great Recession. The model reads as follows:

$$
\Lambda_{i t}=c_{i}+\theta Y_{i t}+\sum_{j} b_{j} *\left(\theta Y_{i t} * X_{i t}^{j}\right)+\epsilon_{i t}
$$

where $\Lambda_{i t}$ is the dependent variable which is either the unemployment rate or a worker flow rate in country $i$ at time $t, c_{i}$ are country dummies, and $Y_{i t}$ denotes the shock in terms of GDP growth. As explained in more detail below, $t$ represents a time period of three years. Furthermore, $X_{i t}^{j}$ is the value of institution $j$ in country $i$ at time $t$. The coefficient of interest, $b_{j}$, quantifies the interaction between shocks and institutions. In particular, the estimate captures the transmission property of the corresponding institution and, thus, depicts the indirect effect of institutions via shocks on the outcome variable.

A distinctive feature of the main coefficient is that institutions enter the model only in the interaction term representing their transmission property for a given shock. We perform non-linear least squares estimations because the shock coefficient is simultaneously estimated as coefficient for the macroeconomic shock alone and for the interaction with institutions. The empirical model accounts for the theoretical mechanisms invoked in Sect. 3, i.e. the same macroeconomic shock may generate very heterogeneous labour market reactions in countries with different institutions.

Note that we do not display the results from the second model that Blanchard and Wolfers (2000) estimate, the unobserved shocks model. This model differs from the one presented above in that it does not explicitly include a shock measure which differs between countries. Instead, it includes time dummmies which are common 
across countries and which serve as a measure of unobserved shocks. This model does not seem appropriate for our purposes as the depth of the Great Recession differed strongly between the countries in our sample. Therefore, the unobserved shocks model yields results which indicate that it is not well-specified (see Bachmann and Felder 2018b, for the results of the unobserved shocks model).

The regression sample is defined as follows. It covers 20 European countries and the US. We split the observation period from 1999 to 2013 into five three-year subperiods, i.e. 1999-2001, 2002-2004, 2005-2007, 2008-2010, and 2011-2013. For each sub-period, we compute averages of yearly unemployment and transition rates, as well as of real annual GDP growth rates. This implies three advantages compared to the use of annual data. First, as argued in Blanchard and Wolfers (2000), the slow movement of institutions only justifies a model in which all variables are summarized over a longer period of time. Second, it diminishes autocorrelation, i.e. it reduces the degree of first-order autocorrelation in the error term, which would lead to wrong standard errors and inference. Finally, business cycle effects are smoothed, allowing us to abstract from short-run labour market reactions. The eight labour market institution measures described in detail in Sect. 3 are constructed as deviations from the cross-country mean following Blanchard and Wolfers (2000). Table A.3 in the online appendix illustrates descriptive statistics of all variables employed in the benchmark regressions.

The main concerns for identification are endogeneity of labour market institutions and shock measures, multicollinearity of the institutional set, autocorrelation and heteroscedasticity. First, endogeneity arises from reverse causality between the evolution of labour markets on the one hand and institutions and shocks on the other hand. Put differently, labour market reforms can take place as a reaction to adverse or advantageous labour market conditions. Second, changes in GDP may be driven by labour market reactions. Therefore, our benchmark specification estimating equation 1 using time-varying institutional measures, is potentially subject to an endogeneity problem. In order to deal with these issues, we follow four strategies. Foremost, we reduce the endogeneity of GDP by using 3-year averages. With respect to institutional endogeneity, we restrict the variation in the institutional variables by considering only their values in the first year for each time window. In addition, we perform a robustness test in which we fix institutions to their level in the first years of our observation period, 1999. Thus, changes in labour market institutions are eliminated after 1999. Finally, we check whether the estimates are sensitive to substituting the measures with their respective 3-year-lagged values.

Multicollinearity between institutional measures arises if the indicators are strongly correlated with each other. As Table A.2 in the online appendix illustrates, this is clearly an issue here. Moreover, institutions change very slowly over time. Therefore, the value of one institution in period $t$ in a country is correlated with the same institution in the adjacent periods. Typically, the consequences of multicollinearity are particularly sensitive estimates and inflated standard errors. Hence, we run both models on five subsets of institutions to check the stability of our estimates.

Finally, autocorrelation and heteroscedasticity are of concern in our regression specification. The application of 3-year-intervals of all variables should reduce the severity of this identification threat. 


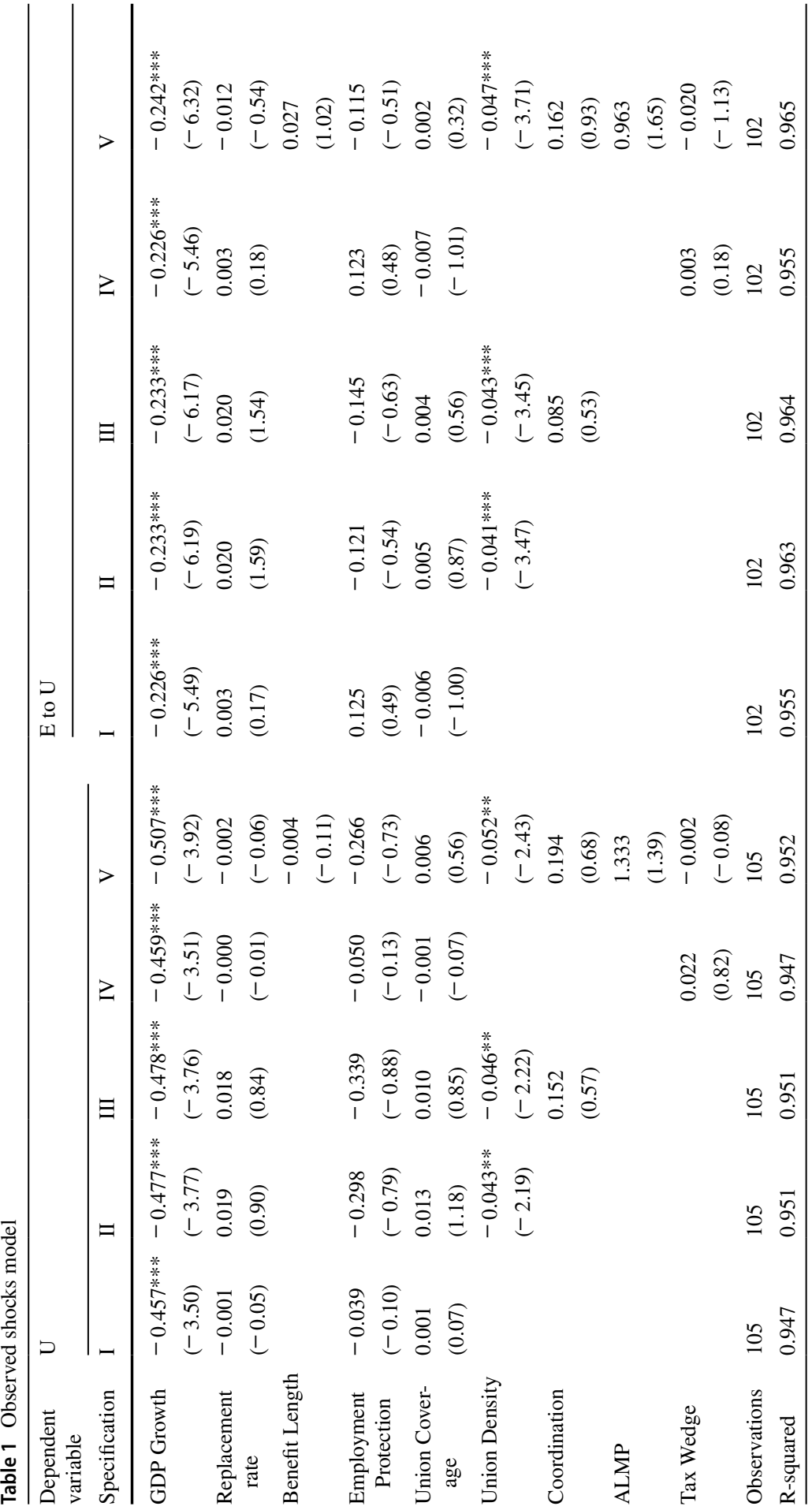




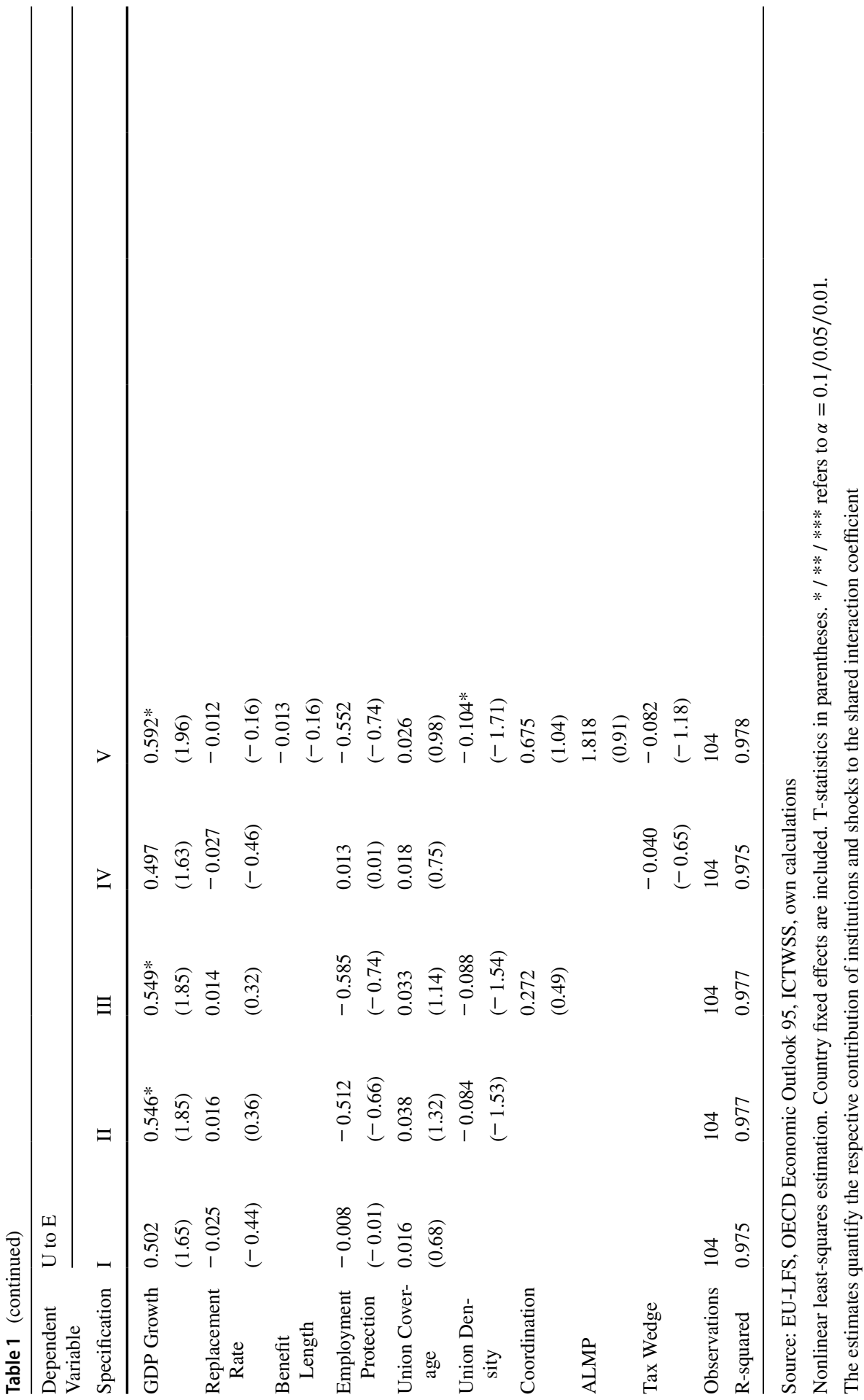




\section{Results}

\subsection{Main analysis}

We begin to examine the role of labour market institutions for the reaction patterns of national labour markets over the business cycle with the baseline model introduced in Sect. 4. As expected, the shock measure in the observed shocks model, the annual GDP growth rate, is highly significant and negatively correlated with the unemployment rate and transitions out of employment (Table 1). The correlation between GDP growth and worker flows from unemployment to employment is positive. The significance of this correlation is not as clear-cut as for the worker flows in the opposite direction, which is not surprising as the matching process on the labour market weakens the influence of the business cycle. Because the institutional variables are demeaned, the coefficient can be interpreted as follows: For countries with mean values for all institutions $(X=0)$ unemployment decreases by about 0.5 percentage points as GDP growth rises by one percentage point. This is very similar to reported coefficients from Okun's Law (Perman et al. 2015).

With respect to the interaction of shocks and institutions, the unemployment benefit system (the replacement rate and the length of benefit entitlements) does not play a role neither for the unemployment rate, nor for worker transitions between employment and unemployment. This is probably due to the fact that our period of analysis is strongly influenced by the Great Recession, i.e. the results are mainly driven by the labour market reactions during an economic downturn. As spelt out in detail in Sect. 3, this means that the impact of the unemployment benefit system can be expected to be relatively weak. The same explanation is likely to apply to the non-significance of ALMP. It is much more important during an economic upswing than during a recession. Again, as our results are mainly driven by the Great Recession, this is a probable explanation for the lack of significance of the variable. The tax wedge is also hardly significant. As it turns out below, this picture changes when looking at different business cycle phases.

The interaction of GDP and employment protection also does not seem to play a role for the evolution of labour markets, both with respect to stocks and flows. For the unemployment stock, this is in line with the literature which does not yield consistent results with respect to the effects of EPL on the unemployment stock (e.g. Bertola 1990; Boeri 1999; Nickell et al. 2005). As for flows, a standard steady-state search-and-matching model such as Mortensen and Pissarides (1994), predicts a clear negative correlation between worker flows and EPL. However, recent crosscountry evidence shows that employment protection does not necessarily reduce transitions from employment to non-employment (Bassanini and Garnero 2013).

Furthermore, the effect of EPL on labour market dynamics seems to be weaker when trend growth is higher, and stronger when trend growth is lower (Bentolila and Bertola 1990; Messina and Vallanti 2007). Our results lend support to this conclusion because the time period analysed includes a relatively long period of sustained growth (i.e. the time period before the Great Recession), which dampens the effect of EPL on worker flows. This picture is corroborated by our separate analysis of upturns and downturns, which is described below. 
(a) Unemployment rate

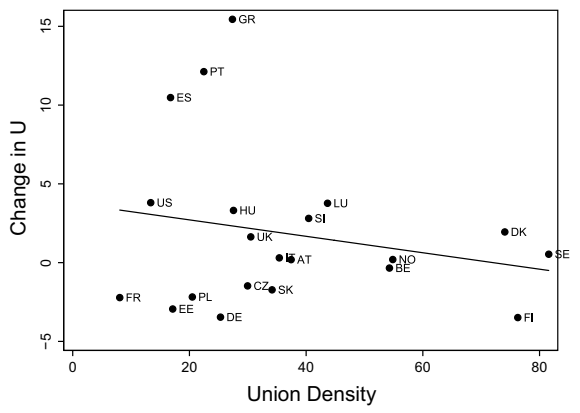

(b) Transition rate from employment to unemployment

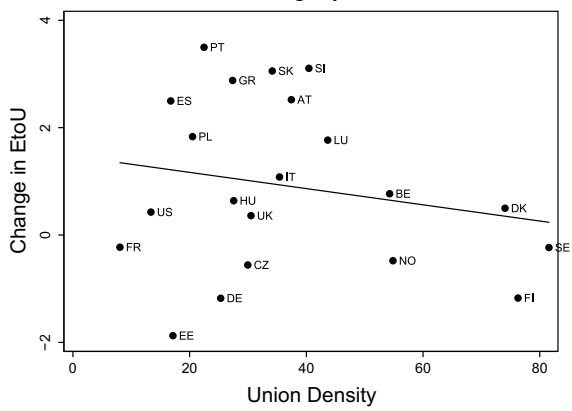

Fig. 4 Relationship between union density and labour market reactions, 1999 and 2013. Notes: See Fig. 1 for the country codes. Source: EU-LFS, CPS, ICTWSS, own calculation

As for the importance of trade unions, coordination and union coverage do not seem to influence the transmission of economic shocks to national labour markets. However, another variable capturing the role of trade unions, union density, is generally significant at conventional levels for all outcomes and specifications. In particular, union density is negatively correlated with the unemployment rate, worker flows from employment to unemployment, as well as worker flows from unemployment to employment (although only weakly so in the latter case). Evaluating the equation for unemployment at a GDP growth of - $1 \%$ implies that an increase in union density of 1 percentage point is associated with a decrease in unemployment of about 0.02 percentage points. Given that union density varies between 6.9 and $81.6 \%$ in our country sample (see Table A.1 in the online appendix), this seems like a large impact. ${ }^{9}$

This relationship can be illustrated by correlating union density with changes in unemployment (Fig. 4, panel (a)) and with changes in the transition rate from employment to unemployment (Fig. 4, panel (b)), where the change considered is between the years 1999 and 2013. From these correlations, it becomes apparent that countries with higher union density experienced a lower increase in unemployment, and lower transition rates from employment to unemployment were a major contributing factor to this. Our findings, in turn, show that this conclusion remains intact when considering the size of the economic shock, particularly in interaction with labour market institutions.

Since it is very consistent across our model specifications, we examine the role of union density in more detail. The estimations suggest that higher union density in a country is associated with more moderate labour market reactions to shocks. The observed pattern may be driven by trade unions aiming to protect employed workers from unemployment, which leads to segregated labour markets. These are characterised by a situation where insiders, i.e. workers employed in stable jobs, gain

\footnotetext{
${ }^{9}$ The findings are robust to using differences in unemployment levels instead of the unemployment level as dependent variable (results available from the authors upon request).
} 
and outsiders, i.e. persons who are not employed or very rarely so, face difficulties to enter the labour market at all. An alternative mechanism by which unions influence labour market dynamics is an adjustment at the intensive margin such as the reduction of working hours during the Great Recession, implemented for example in Germany by a short-time work scheme. However, for our main finding, the indirect influence of union density, using working hours provided by Ohanian and Raffo (2012), we find in the Great Recession period neither a negative correlation between union density and working hours nor a statistically significant negative relationship using fixed effects OLS regression techniques. Therefore, there seems to be no link between union density and the intensive margin. ${ }^{10}$ Following either of these lines of reasoning - segregated labour markets or adjustment along the intensive margin -, we expect to find that union density relates to lower unemployment outflows during economic growth periods and lower employment outflows in recessions.

To test this hypothesis, we conduct two regressions in which we measure the relationship between institutions and shocks by economic boom or bust periods. Accordingly, we include in the interaction term a growth or recession dummy, respectively. ${ }^{11}$ Hence, the model still comprises the intensity of the shock. In the preceding analysis we have used 3-year-intervals instead of yearly observations to account for potential endogeneity in the shock and institution measures between the years. For this investigation we now rely on annual data in order to have sufficient observations. ${ }^{12}$ Indeed, Tables A.5 and A.6 in the online appendix support the notion that union membership is related with more robust labour market reactions over the business cycle. The coefficients on union density imply countries with a high union membership display a smaller reduction in unemployment during an economic upturn. The same result materialises in recessions, i.e. strong union density reduces the adverse impact on the unemployment rate. The results for the worker flows confirm these findings.

Furthermore, the separate analysis with respect to business cycle periods shows that in economic growth periods, the level of wage coordination amplifies national labour market reactions. The opposite holds true for recession periods. Therefore, a high level of wage coordination is a favourable influence, which is in line with the literature, among others Bassanini and Duval (2006), Gal and Theising (2015) and Bertola (2017). Moreover, during recessions the benefit length and the tax wedge intensify, whereas EPL weakly cushions the adverse effects on the labour market. The first result can be explained by a longer benefit length slowing down the unemployment exit rate; however, this result seems particular to the Great Recession, as research for earlier time periods has shown that the unemployment benefit system plays a more important role in boom than in recession periods (Schmieder et al. 2012). The

\footnotetext{
10 Additionally, we include the share of short-time workers and hours worked in the benchmark regression. The findings remain robust to these alterations (results available from the authors upon request).

11 This means that in equation 1 , we use $Y_{i t} * X_{i t}^{j} * D_{i t}$ instead of $Y_{i t} * X_{i t}^{j}$, where $D_{i t}$ takes the value 1 in case of a recession, and 0 otherwise, or the reverse in case of an economic boom. A recession is defined as a negative or zero yearly GDP growth rate. Accordingly, an economic boom is defined by a positive GDP growth rate.

12 Table A.4 in the online appendix displays the estimates of the benchmark model using annual data. The results are very similar compared to applying three-year windows.
} 
negative link with the tax wedge is in line with existing research (Belot and Van Ours 2004; Nickell 1997). Interestingly, this result only materialises in the recession sample, which can be viewed as an indication that the negative labour-demand effects described in Sect. 3 play a dominant role in this context. The result on EPL stands in contrast to the non-significant effect of EPL on labour market flows indicated above for the entire time period. However, our finding of a significantly negative effect of EPL for recession periods is in line with and confirms the result by Bentolila and Bertola (1990) and Messina and Vallanti (2007) that the impact of EPL is stronger the weaker trend growth is, as well as evidence on the stabilising role of EPL on job tenure during the Great Recession in Europe (Bachmann and Felder 2018a).

Overall, our investigation indicates that institutional variables related to trade unions exhibit explanatory power for the prevailing patterns in labour market dynamics across countries. Specifically, we find that the interaction of shocks with union density weakens labour market reactions. Strong trade unions tend to reduce both employment growth in economic upturns and employment losses in downturns, which overall results in more moderate reactions of the unemployment rate over the business cycle.

\subsection{Robustness}

In order to support our conclusions with respect to the determining role of trade unions in shaping unemployment and worker transitions between employment and unemployment, we run a battery of robustness tests.

First, we present estimates testing for endogeneity in our benchmark regression. Endogeneity poses a threat for identification, because of the potential for reverse causality between the evolution of national labour markets on the one hand, and institutions and shocks on the other hand. Institutional reforms may be induced by unfavourable labour market conditions, and changes in labour market dynamics may influence the business cycle, respectively. We therefore run regressions with (i) institution measures lagged by one period and (ii) institution measures fixed at their values for the year 1999 instead of using contemporary values.

The results of these sensitivity tests show that generally, our benchmark conclusions are robust (Tables A.7 and A.8 in the online appendix). In particular, the moderating role of trade unions for labour markets is a consistent result. However, in the specifications controlling for union density, the lagged model indicates that union coverage adversely influences worker flows from employment to unemployment. This points to the two opposing features of trade unions discussed in Sect. 3. On the one hand, trade unions establish wage rigidities which reinforce negative macroeconomic shocks, while on the other hand trade unions aim at making jobs more secure, which has effects in the opposite direction.

To investigate the endogenous nature of the GDP growth rate with unemployment we run Granger causality tests. The results suggest that reverse causality is not an important concern for most countries since we can reject for 15 countries that unemployment Granger causes GDP growth. Furthermore, we replace the GDP growth rate with its one period lagged value as well as with alternative measures for macroeconomic conditions, i.e. the output gap, the real interest rate and total factor 
productivity growth. These robustness tests do not change our results and conclusions significantly (results available from the authors upon request).

Second, we assess the sensitivity of our benchmark model to changes in the sample. We exclude countries that represent extreme cases with respect to the intensity of the Great Recession. Portugal, which was hit strongly by the economic recession and which features very strong employment protection, is omitted in Table A.9 in the online appendix. The smoothing behaviour of trade unions on labour market dynamics over the business cycle is confirmed by the regression. Additionally, the estimates without the observations of Portugal imply that the effects of a negative economic shock on national labour markets are less pronounced in countries with higher EPL, which is line with the investigation of economic upturns only. Excluding Germany (Table A.10 in the online appendix), a country where the labour market was hardly affected by the Great Recession, also leaves the conclusions of the main specification intact. Additionally, we run separate regressions where we remove two country groups (the Nordic and the East European Countries), and individual countries (Belgium, Denmark, France, Spain and the US) from the sample. The findings are robust to these alterations (results available from the authors upon request). Moreover, we estimate the influence of institutions on labour markets separately by gender and for young and old individuals. Institutions have a higher relevance for men and young individuals (results available from the authors upon request).

Third, we check the robustness by accounting for temporary employment. Since temporary workers are less costly to lay off for firms than regular workers, the share of temporary employees is an indicator for the flexibility of labour markets. We expect that countries with a high rate of temporary workers experience higher adverse reactions in unemployment and in worker outflows from employment. Indeed, Table A.11 in the online appendix provides evidence for this perception. Controlling for temporary employment, the transition rate from employment to unemployment is not adversely influenced by union coverage as suggested by other specifications. This may be due to the additional collinearity imposed on the model. Nevertheless, the robustness test confirms the importance of union density in influencing national labour markets.

Fourth, we assess whether including movements out of the labour force change our main results. This is of interest as it has been argued that such worker flows are an important aspect of the cyclical features of the labour market (Ebell 2011). We therefore extend our analysis to aggregate employment outflows to both unemployment and nonparticipation. The corresponding results presented in Table A.12 in the online appendix are similar to the estimation results for transitions from employment to unemployment. Therefore, taking into account the participation margin does not alter our main results. ${ }^{13}$

Finally, for our analysis distinguishing between booms and recessions, instead of running regressions on separate estimation samples, we run the regressions on the pooled sample and include asymmetric interaction effects for economic recession

\footnotetext{
13 This is also the case when conducting this robustness test for the inflow into inactivity for young workers only (results available from the authors upon request).
} 
and boom periods. This yields very similar results to the regressions on separate samples.

\section{Conclusion}

In this paper, we examine the reasons for cross-country differences in labour market dynamics for a large number of European countries as well as the US for the time period 1999 to 2013. Thereby, we focus on both the unemployment rate and worker flows between employment and unemployment, which we compute from micro data at the worker level. In our analysis, we employ the methodology of Blanchard and Wolfers (2000) to separately identify the impact of shocks on the one hand, and the transmission of shocks to national labour markets through the institutional framework on the other hand. We thus extend the existing literature by (i) explicitly analysing worker flows, in addition to the unemployment rate, and (ii) analysing the time period of the Great Recession as well as the preceding decade.

Our results suggest that institutions play an important channeling role of macroeconomic shocks to national labour markets. While this is not the case for the unemployment benefit system, the results of our empirical analysis provide evidence for the importance of trade unions in this context. Specifically, union density, i.e. the share of union members, relates to more moderate labour market reactions to shocks. This result is more pronounced for worker flows from employment to unemployment than for worker flows from unemployment to employment. In particular, the analysis shows that trade unions tend to reduce employment growth in economic upturns and employment contractions in recessions. As a result, the unemployment rate in countries with stronger trade unions features a lower variation over the business cycle. Our results furthermore confirm findings from the literature that employment protection legislation becomes more important for labour market flows when the trend growth of the economy is low (e.g. Bentolila and Bertola 1990; Messina and Vallanti 2007). Finally, we show the negative link between the tax wedge and unemployment only materializes in the recession and is therefore likely to be driven by labour-demand considerations.

In order to analyse the robustness of our results, we conduct a number of tests. It turns out that the potential endogeneity of both shocks and institutions, country outliers with respect to institutions and the depth of the recession, and the importance of temporary employment in national labour markets do not significantly affect our analysis. Furthermore, including the participation margin, i.e. worker transitions out of the labour market, also does not alter our main conclusions.

Our results with respect to trade unions, i.e. that union density is associated with lower unemployment and lower inflows into unemployment, stand in contrast to Blanchard and Wolfers (2000) and Nickell (1997) who show that up to the mid1990s strong unions were positively associated with unemployment. However, the results are partially in line with Bassanini and Duval (2006) who study a more recent period from 1982 to 2003 and who also find a dampening role of unions. Moreover, there is recent evidence from a number of European countries which shows that 
union membership reduces a person's layoff probability (Goerke and Pannenberg 2011; Ivlevs and Veliziotis 2017; Pierse and McHale 2015).

The welfare implications of our results with respect to trade unions are not clearcut. On the one hand, lower volatility of unemployment (i.e. lower unemployment inflows and outflows) is associated with higher subjective well-being (Wolfers 2003), which means that unions would be welfare-enhancing. On the other hand, lower volatility of unemployment is likely to go together with a lower permeability of labour markets. This implies the existence of segregated labour markets where a part of the workforce benefits from stable employment relationships while another part of the workforce has great difficulties entering the labour market or only attains low-paid and/or unstable jobs. In this respect, unions would be welfare-decreasing.

Against this background, two lines of further research appear particularly interesting. First, the exact mechanisms by which unions reduce unemployment fluctuations should be investigated, which only appears possible with linked employeremployee data containing information on both the worker and the firm side. Second, dual labour markets imply the existence of winners and losers. It is therefore of great interest to examine which groups of the population gain and which ones lose out because of lower employment volatility, which would also allow for a rigorous analysis of the welfare effects indicated above.

Electronic supplementary material The online version of this article (https://doi.org/10.1007/s10663019-09469-y) contains supplementary material, which is available to authorized users.

Funding Open Access funding enabled and organized by Projekt DEAL.

Open acess This article is licensed under a Creative Commons Attribution 4.0 International License, which permits use, sharing, adaptation, distribution and reproduction in any medium or format, as long as you give appropriate credit to the original author(s) and the source, provide a link to the Creative Commons licence, and indicate if changes were made. The images or other third party material in this article are included in the article's Creative Commons licence, unless indicated otherwise in a credit line to the material. If material is not included in the article's Creative Commons licence and your intended use is not permitted by statutory regulation or exceeds the permitted use, you will need to obtain permission directly from the copyright holder. To view a copy of this licence, visit http://creativecommons.org/licen ses/by/4.0/.

\section{References}

Bachmann R, Felder R (2018a) Job stability in Europe over the cycle. Int Labour Rev 3(157):481-516

Bachmann R, Felder R (2018b) Labour market transitions, shocks and institutions in turbulent times: a cross-country analysis. IZA Discussion Papers 11443, Institute of Labor Economics (IZA). https:// ideas.repec.org/p/iza/izadps/dp11443.html

Bachmann R, Bechara P, Kramer A, Rzepka S (2015) Labour market dynamics and worker heterogeneity during the Great recession-Evidence from Europe. IZA J Eur Labor Stud 4(1):19

Bassanini A, Duval R (2006) The determinants of unemployment across OECD countries: reassessing the role of policies and institutions. OECD Econ Stud 42(1):7-86

Bassanini A, Garnero A (2013) Dismissal protection and worker flows in OECD countries: evidence from cross-country/cross-industry data. Labour Econ 21:25-41

Belot M, Van Ours JC (2004) Does the recent success of some OECD countries in lowering their unemployment rates lie in the clever design of their labor market reforms? Oxford Econ Papers 56(4):621-642 
Bentolila S, Bertola G (1990) Firing costs and labour demand: how bad is eurosclerosis? Rev Econ Stud 57(3):381-402

Bertola G (1990) Job security, employment and wages. Eur Econ Rev 34(4):851-879

Bertola G (2017) European unemployment revisited: shocks, institutions, integration. Res Econ 3(71):588-612

Bertola G, Rogerson R (1997) Institutions and labor reallocation. Eur Econ Rev 41(6):1147-1171

Blanchard O (1999) European unemployment: the role of shocks and institutions. Baffi Lecture Rome

Blanchard O, Wolfers J (2000) The role of shocks and institutions in the rise of European unemployment: the aggregate evidence. Econ J 110(462):1-33

Boeri T (1999) Enforcement of employment security regulations, on-the-job search and unemployment duration. Eur Econ Rev 43(1):65-89

Boeri T, Van Ours J (2013) The economics of imperfect labor markets. Princeton University Press, Princeton

Burda MC, Hunt J (2011) What explains the German labor market miracle in the great recession? Brook Papers Econ Act 2011(1):273-319

Burda MC, Weder M (2016) Payroll taxes, social insurance, and business cycles. J Eur Econ Assoc 14(2):438-467

Card D, Kluve J, Weber A (2010) Active labour market policy evaluations: a meta-analysis. Econ J 120(November):F452-F477

Card D, Kluve J, Weber A (2018) What works? A meta analysis of recent active labor market program evaluations. J Eur Econ Assoc 16(3):894-931

de Serres A, Murtin F (2013) Do policies that reduce unemployment raise its volatility? OECD Economics Department Working Paper 1020

Ebell M (2011) On the cyclicality of unemployment: resurrecting the participation margin. Labour Econ 18(6):822-836

Eichhorst W, Feil M, Marx P (2010) Crisis, what crisis? Patterns of adaptation in European labor markets. Appl Econ Q 61(Supplement):29-64

Elsby M, Hobijn B, Sahin A (2013) Unemployment dynamics in the OECD. Rev Econ Stat 95(2):530-548

Elsby MW, Michaels R, Solon G (2009) The ins and outs of cyclical unemployment. Am Econ J Macroecon 1(1):84-100

European Central Bank (2012) Euro are labour markets and the crisis. ECB Occasional Paper Series 138

Eurostat (2014) Harmonized unemployment rate. http://epp.eurostat.ec.europa.eu/tgm/table.do?tab=table $\&$ language $=$ en $\&$ pcode $=$ teilm020. Accessed 3 Feb 2014

Flaig G, Rottmann H (2013) Labour market institutions and unemployment: an international panel data analysis. Empirica 40(4):635-654

Flood S, King M, Ruggles S, Warren JR (2015) Integrated public use microdata series, Current Population Survey: Version 4.0. [Machine-readable database]. Tech rep, University of Minnesota, Minneapolis

Freeman RB (1978) A fixed effect logit model of the impact of unionism on quits. NBER Working Paper 280

Fujita S, Ramey G (2009) The cyclicality of separation and job finding rates. Int Econ Rev 50(2):415-430

Gal P, Theising A (2015) The macroeconomic impact of policies on labour market outcomes in OECD countries. OECD Economics Department Working Paper 1271

Goerke L, Pannenberg M (2011) Trade union membership and dismissals. Labour Econ 18(6):810-821

Hijzen A, Martins PS (2016) No extension without representation? Evidence from a natural experiment in collective bargaining. International Monetary Fund Working Paper 16/143

ILO (1988) Current International Recommendations on Labour Statistics, 1988 Edition. International Labour Organisation, Geneva

Ivlevs A, Veliziotis M (2017) What do unions do in times of economic crisis? Evidence from Central and Eastern Europe. Eur J Ind Relat 23(1):81-96

Layard PRG, Nickell SJ, Jackman R (2005) Unemployment: macroeconomic performance and the labour market. Oxford University Press, Oxford

Layard R, Nickell SJ, Jackman R (1991) Unemployment: macroeconomic performance and the labour market. Oxford University Press, Oxford

McDonald IM, Solow RM (1981) Wage bargaining and employment. Am Econ Rev 71(5):896-908

Medoff JL (1979) Layoffs and alternatives under trade unions in US manufacturing. Am Econ Rev 69(3):380-395

Messina J, Vallanti G (2007) Job flow dynamics and firing restrictions: evidence from europe. Econ J 117(521):F279-F301 
Mortensen DT, Pissarides CA (1994) Job creation and job destruction in the theory of unemployment. Rev Econ Stud 61(3):397-415

Mortensen DT, Pissarides CA (1999) New developments in models of search in the labor market. In: Ashenfelter O, Card D (eds) Handbook of labor economics, 1st edn. Elsevier, Amsterdam, pp 25672627 Chapter 39

Nickell S (1997) Unemployment and labor market rigidities: Europe versus North America. J Econ Perspect 11(3):55-74

Nickell S, Nunziata L, Ochel W (2005) Unemployment in the OECD since the 1960s. What do we know?*. Econ J 115(500):1-27

Nickell S, Andrews M (1983) Unions, real wages and employment in Britain 1951-79. Oxford Econ Papers 35(Suppl):183-206

Nunziata L (2002) Unemployment, labour market institutions and shocks. Economics Series Working Papers 2002-w16

OECD (2013) OECD Employment Outlook 2013. OECD Publishing, Paris

Ohanian LE, Raffo A (2012) Aggregate hours worked in OECD countries: new measurement and implications for business cycles. J Monet Econ 59(1):40-56

Orlandi F (2012) Structural unemployment and its determinants in the EU countries. European EconomyEconomic Papers 455, Directorate General Economic and Monetary Affairs (DG ECFIN), European Commission

Perman R, Stephan G, Tavera C (2015) Okun's Law-A meta-analysis. Manch Sch 83(1):101-126

Petrongolo B, Pissarides CA (2008) The ins and outs of European unemployment. Am Econ Rev 98(2):256-262

Pierse T, McHale J (2015) Unions and involuntary job separations. Human Resour Manag J 496-515(25):4

Scarpetta S (1996) Assessing the role of labour market policies and institutional settings on unemployment: a cross-country study. OECD Econ Stud 26(1):43-98

Schmieder JF, von Wachter T (2016) The effects of unemployment insurance benefits: new evidence and interpretation. Ann Rev Econ 8:547-581

Schmieder JF, von Wachter T, Bender S (2012) The effects of extended unemployment insurance over the business cycle: evidence from regression discontinuity estimates over 20 years. Q J Econ 127(2):701-752

Traxler F, Kittel B (2000) The bargaining system and performance a comparison of 18 OECD countries. Comp Polit Stud 33(9):1154-1190

Wolfers J (2003) Is business cycle volatility costly? Evidence from surveys of subjective well-being. Int Fin 6(1):1-26

Yashiv E (2008) U.S. labor market dynamics revisited. Scand J Econ 109(4):779-806

Publisher's Note Springer Nature remains neutral with regard to jurisdictional claims in published maps and institutional affiliations.

\section{Affiliations}

\section{Ronald Bachmann $^{1,2,3,4} \cdot$ Rahel Felder $^{1,5}$}

Rahel Felder

Rahel.Felder@rwi-essen.de

1 RWI - Leibniz-Institut für Wirtschaftsforschung, Essen, Germany

2 Düsseldorf Institute for Competition Economics (DICE), Düsseldorf, Germany

3 Heinrich-Heine-Universität Düsseldorf, Düsseldorf, Germany

4 Forschungsinstitut zur Zukunft der Arbeit (IZA), Bonn, Germany

5 Ruhr-Universität Bochum (RUB), Bochum, Germany 